\title{
Consistere in o consistere di?
}

\section{Giuseppe Patota}

PUBBLICATO: 08 FEBBRAIO 2019

\section{Quesito:}

Diversi utenti chiedono quale preposizione debba seguire il verbo consistere.

\section{Consistere in o consistere di?}

Bisogna dire e scrivere "consistere di qualcosa" o "consistere in qualcosa"? Oppure, sono possibili entrambe le costruzioni?

La risposta è semplice: dipende dal significato che assume, nel contesto dato, il verbo consistere. Se consistere significa 'essere basato' (evidentemente, su qualcosa), allora richiede la preposizione in, come negli esempi che seguono: "L'esame consisterà in una prova scritta e in una prova orale"; "In che cosa consiste il tuo lavoro?"; "L'abilità del giocatore consiste nel saper prevedere le mosse dell'avversario".

Invece, se consistere significa 'essere costituito', 'essere formato', 'essere fatto' (evidentemente, da qualcosa), allora richiede la preposizione di, come negli esempi che seguono: "La mia colazione consiste di latte e biscotti"; "L'enciclopedia consiste di venti volumi".

Di solito, concludo le mie risposte con un generico riferimento ai quattro o cinque (ottimi) vocabolari che descrivono il lessico dell'italiano contemporaneo; in questo caso, è d'obbligo che io renda onore al merito, precisando che l'unico dizionario che applica questa distinzione con encomiabile chiarezza è quello diretto da Francesco Sabatini e Vittorio Coletti,

il Sabatini Coletti. Dizionario della Lingua Italiana 2008 con allegato CD-ROM, Milano, RCS Libri, 2007.

\section{Cita come:}

Giuseppe Patota, Consistere in o consistere di?, “Italiano digitale”, 2019, VIII, 2019/1 (gennaiomarzo), pp. 19.

DOI: $10.35948 / 2532-9006 / 2019.3066$ 